Elsevier Editorial System(tm) for European Journal of Obstetrics \& Gynecology and Reproductive Biology or its open access mirror

Manuscript Draft

Manuscript Number: EJOGRB-20-21852R2

Title: Diagnosis and outcome of hydatidiform moles in missed-miscarriage: a cohort-study, systematic review and meta-analysis

Article Type: Full Length Article

Section/Category: Gynaecology

Keywords: Hydatidiform mole

Complete mole

Partial mole

Ultrasound imaging

Miscarriage

Gestational trophoblastic neoplasia

Corresponding Author: Professor Eric Jauniaux, MD, PhD, FRCOG

Corresponding Author's Institution: Royal Free and University College London

First Author: Maria Memtsa

Order of Authors: Maria Memtsa; Jemma Johns; Davor Jurkovic; Jackie A Ross; Neil J Sebire; Eric Jauniaux, MD, PhD, FRCOG

Abstract: Objective: To evaluate the ultrasound diagnostic rates of complete hydatidiform moles (CHM) and partial hydatidiform moles (PHM) in women presenting with a missed miscarriage, the clinical complications at diagnosis and the risk of gestational trophoblastic neoplasia (GTN) after surgical evacuation and to compare our findings with those of the published literature by completing a systematic review and meta-analysis Study design: Retrospective review of the data of 295 women diagnosed with a histologically confirmed hydatidiform moles (HM) over a 15-year period, including $128 \mathrm{CHM}$ and 167 PHM. All women were referred to a regional specialist centre for follow-up and further management. An electronic search of PubMed, Google Scholar and MEDLINE was performed for studies published between september 1973 and September 2017 reporting on the early ultrasound diagnosis of hydatidiform mole. Only cohort studies which provided ultrasound data confirmed by histopathology were included. Results: In the cohort study, ultrasound imaging diagnosed a significantly $(p<0.001)$ higher number of CHM $(95 / 128$ (74.2\%) than PHM $(68 / 167$ (40.7\%). Ovarian theca lutea cysts were observed in three CHM and one PHM. There were no cases of pre-eclampsia or thyrotoxicosis at the time of diagnosis. Maternal serum $\beta$-human chorionic gonadotrophin levels were abnormally low ( $<0.5$ MoM) in 5/51 (10\%) CHM and 23/43 (53\%) PHM and abnormally high (> 2.0 MoM) in 20/51 (39\%) CHM and 2/43 (5\%) PHM. Seventeen (12.3\%) CHM and two (1.4\%) PHM GTN requiring treatment. In the literature the proportion of histologically diagnosed HM, suspected on ultrasound in early pregnancy, ranged between 34.2 and $90.2 \%$ for HM, 57.8 and 95\% for CHM and 17.6 and 51.6\% for PHM. The meta-analysis indicated 
substantial heterogeneity in the overall ultrasound diagnosis of HM and in the differential diagnosis between CHM and PHM.

Conclusion(s): As around a third of CHM and two thirds of PHM are not diagnosed on ultrasound in cases of missed miscarriage, histopathological examination of all products of conception in case of early pregnancy failure is essential to detect molar changes. This is particularly important for the management of women with CHM who have a higher risk of developing a GTN. 


\section{ANSWER TO THE REVIEWERS COMMENTS}

Ref.: Ms. No. EJOGRB-20-21852, "Diagnosis and outcome of hydatidiform moles in missed-miscarriage: a cohort-study, systematic review and meta-analysis"

Reviewer \#1: This is an interesting manuscript comparing a retrospective cohort with previous similar studies regarding complete and partial hydatidiform moles.

At the same time demonstrate the usefulness of histological examinations of remains in case of early pregnancy loss. This is the main strength of the manuscript.

The stringent criteria for both, the cohort study and meta-analysis make the conclusions trustworthy.

It would be desirable to cluster the studies in meta-analysis by region/country, particularly in underdeveloped countries. In this way, the comparisons could be more useful.

I recommend to include those data in the analysis.

We thank the reviewer for his comment and have changed table 1 to order the studies according to their country of origin. There were no studies from low-income countries.

Reviewer \#2: The article reviews the importance of routine histological examination of products of conceptus following early pregnancy failure. It relies on the strength of a retrospective study of cases from two reputed centres in the UK and draws comparison from literature of similar studies through systematic review and meta- analysis. The study is very relevant to current clinical practice as many centres are contemplating or already have abandoned the practice of sending early pregnancy tissue for histological examination following miscarriage. It also shows the accuracy of diagnosing $\mathrm{CHM}$ and PHM on ultrasound scan and highlights the importance of missing molar pregnancy and subsequent sequelae with GTN. I think this article will be highly relevant to policy makers both locally and nationally.

Overall the article is balanced and methodologically sound. 


\section{Diagnosis and outcome of hydatidiform moles in missed-miscarriage: a cohort- study, systematic review and meta- analysis}

Maria Memtsa ${ }^{a}$, Jemma Johns ${ }^{b}$, Davor Jurkovic ${ }^{a}$, Jackie A Ross ${ }^{b}$, Neil J Sebire ${ }^{c}$, Eric Jauniaux ${ }^{\mathrm{a},{ }^{*}}$

a EGA Institute for Women's Health, Faculty of Population Health Sciences, University College London (UCL), London, UK

b Early Pregnancy and Gynaecology Assessment Unit, Kings College Hospital, London, UK.

${ }^{c}$ Great Ormond Street Institute of Child Health, University College London (UCL) London, UK

\section{Disclosure statement}

The authors have no conflict of interest to declare.

\section{Funding}

No funding was obtained for this project.

Word count: main text $=3265$ / Abstract $=346$

Corresponding author: Professor Eric Jauniaux, Institute for Women's Health, University College London, 86-96 Chenies Mews, London WC1E 6HX, UK.

Telephone numbers: $+44 / 207 / 3908113$

Fax: +44/207/3908115

E-mail: e.jauniaux@ucl.ac.uk 


\begin{abstract}
Objective: To evaluate the ultrasound diagnostic rates of complete hydatidiform moles ( $\mathrm{CHM})$ and partial hydatidiform moles $(\mathrm{PHM})$ in women presenting with a missed miscarriage, the clinical complications at diagnosis and the risk of gestational trophoblastic neoplasia (GTN) after surgical evacuation and to compare our findings with those of the published literature by completing a systematic review and meta-analysis

Study design: Retrospective review of the data of 295 women diagnosed with a
\end{abstract} histologically confirmed hydatidiform moles (HM) over a 15-year period, including $128 \mathrm{CHM}$ and $167 \mathrm{PHM}$. All women were referred to a regional specialist centre for follow-up and further management. An electronic search of PubMed, Google Scholar and MEDLINE was performed for studies published between September 1973 and September 2017 reporting on the early ultrasound diagnosis of hydatidiform mole. Only cohort studies which provided ultrasound data confirmed by histopathology were included.

Results: In the cohort study, ultrasound imaging diagnosed a significantly $(p<0.001)$ higher number of CHM (95/128 $(74.2 \%)$ than PHM (68/167 (40.7\%). Ovarian theca lutea cysts were observed in three $\mathrm{CHM}$ and one PHM. There were no cases of pre-eclampsia or thyrotoxicosis at the time of diagnosis. Maternal serum $\beta$-human chorionic gonadotrophin levels were abnormally low $(<$ $0.5 \mathrm{MoM}$ ) in 5/51 (10\%) CHM and 23/43 (53\%) PHM and abnormally high (> 2.0 MoM) in 20/51 (39\%) CHM and 2/43 (5\%) PHM. Seventeen (12.3\%) CHM and two (1.4\%) PHM GTN requiring treatment. In the literature the proportion of 
histologically diagnosed $\mathrm{HM}$, suspected on ultrasound in early pregnancy, ranged between 34.2 and $90.2 \%$ for $\mathrm{HM}, 57.8$ and $95 \%$ for $\mathrm{CHM}$ and 17.6 and $51.6 \%$ for

PHM. The meta-analysis indicated substantial heterogeneity in the overall ultrasound diagnosis of $\mathrm{HM}$ and in the differential diagnosis between $\mathrm{CHM}$ and PHM.

Conclusion(s): As around a third of CHM and two thirds of PHM are not diagnosed on ultrasound in cases of missed miscarriage, histopathological examination of all products of conception in case of early pregnancy failure is essential to detect molar changes. This is particularly important for the management of women with CHM who have a higher risk of developing a GTN.

\section{Key Words:}

Hydatidiform mole

Complete mole

Partial mole

Ultrasound imaging

Miscarriage

Gestational trophoblastic neoplasia 


\subsection{Introduction}

Hydatidiform moles (HM) are characterized by villous mesenchymal tissue swelling and trophoblastic hyperplasia, the presence of which confirms the diagnosis on histologic examination [1,2]. HMs are classified into either complete hydatidiform moles (CHM) where the trophoblastic hyperplasia is diffuse, fetal development is absent and the morphological changes are generalised, or partial hydatidiform moles (PHM) which characteristically display trophoblastic hyperplasia with focal villous hydropic changes and evidence of fetal development [3-5].

The incidence of $\mathrm{CHM}$ is estimated at around 1 per 1000 births in the UK and USA [1,2] but it varies around the world [6] and is higher in adolescents and women with advanced maternal age [7]. The estimated incidence of PHM is 1 per 700 pregnancies including triploid PHMs which represent more than $90 \%$ of cases [5]. Following uterine evacuation, $15-20 \%$ of patients with a $\mathrm{CHM}$ develop gestational trophoblastic neoplasia (GTN) requiring chemotherapy [1,2]. By contrast, the risk of GTN following the uterine evacuation of a PHM is well less defined with incidences ranging between 0.5 and $10 \%$ [8-12]. Measuring the levels of total or $\beta$-human chorionic gonadotrophin ( $\beta$-hCG) in maternal serum (MS) or urine have been pivotal in the follow-up and management of these conditions $[1,2,13,14]$ but has rarely been used in the diagnosis of HMs in women presenting with an early pregnancy failure.

Before the advent of ultrasound imaging, HMs were only suspected around mid-gestation on the basis of clinical symptoms, such as chronic vaginal bleeding, excessive uterine enlargement, severe hyperemesis, early onset preeclampsia, eclampsia and thyrotoxicosis and high hCG levels in maternal urine 
$[15,16]$. In fact, one of the first uses of ultrasound in obstetrics was for the prenatal diagnosis of $\mathrm{CHM}[17,18]$. Early cohort studies have shown the high accuracy of ultrasound imaging in diagnosing $\mathrm{CHM}$ in the second trimester of pregnancy [19-20]. With the increased use of high-resolution transvaginal ultrasound (TVS) in early pregnancy, the diagnosis of both CHM and PHM has moved from the second trimester to the first trimester [21-27]. Ultrasound imaging has also progressively replaced invasive radiological techniques, such as angiography, in the follow-up of women with GTN [20].

The molar transformation of the placental tissue in $\mathrm{HM}$ is a progressive phenomenon secondary to the oedema of the villous mesenchyme and the typical cystic molar changes found on ultrasound are often not visible before 9 weeks of gestation [28]. The vast majority of $\mathrm{CHM}$ and triploid PHM miscarry spontaneously during the first three months of pregnancy and it has been estimated that the incidence of $\mathrm{HM}$ is higher in early than in late pregnancy losses [3]. Women presenting with an early pregnancy failure (whether early embryonic demise, incomplete or complete miscarriage) will only have a histological examination if they opt for surgical management. Therefore, if a HM is not diagnosed at the time of the sonographic examination, women are at risk of delayed treatment should persistent GTN develops. The purpose of the present study was to evaluate the detection rates of histologically confirmed $\mathrm{CHM}$ and PHM in women presenting with a missed-miscarriage, the clinical complications at diagnosis and the risk of gestational trophoblastic neoplasia (GTN) after 
surgical evacuation and to compare our findings with those of the published literature by completing a systematic review and meta-analysis.

\subsection{Materials and Methods}

Women diagnosed histologically with a HM who had an ultrasound examination at $\leq 13$ weeks of gestation at the Early Pregnancy Assessment Unit (EPAU) at University College London (UCLH) and King's College Hospital (KCH) in London, UK between March 2003 and December 2017 were included in the study. All women presenting to the Early Pregnancy Unit (EPU) with a positive pregnancy test and symptoms of early pregnancy complications are offered a high-resolution transvaginal ultrasound examination as part of their medical assessment. All TVS examinations are carried out by a research fellow in obstetrics and gynaecology or by a sonographer, supervised by experienced specialists. All pregnancies were dated according to the last menstrual period (LMP) confirmed by gestational sac diameter and/or by fetal crown-rump length $(\mathrm{CRL})$ in ongoing pregnancies. Women presenting with ultrasound features indicating an early pregnancy failure (missed miscarriage or incomplete miscarriage) are offered surgical evacuation or conservative management with follow-up in line with the local protocols.

The population studied included all cases of histologically confirmed CHM and PHM who had an ultrasound examination in one of the two EPAUs. The ultrasound diagnosis of suspected HM was made contemporaneously in both units using the following ultrasound signs: for $\mathrm{CHM}$, diffuse villous hydropic 
changes occupying the entire uterine cavity lumen with no fetus/embryo and for PHM, placental enlargement with focal villous hydropic changes and an amniotic sac containing a fetus/fetal remnant or empty [28]. Surgical management of miscarriage is recommended for all women with suspected HM on TVS. All evacuated surgical tissue is sent for routine histological examination and reviewed by a specialist pathologist if suspected of hydatidiform changes and/or trophoblastic hyperplasia.

All the cases diagnosed in our units are registered for follow-up with the regional gestational trophoblastic disease service at Charing Cross Hospital (www.hmole-chorio.org.uk), Imperial College, London, UK. MS $\beta$-hCG levels are not routinely obtained at the time of the ultrasound examination but after registration urine samples are taken monthly for measurement of the $\beta$-hCG level for 6 months if the level has reverted to normal with 56 days post-surgery or 6 months from normalisation of the level.

The protocol and a waiver of consent were approved by the NHS Health Research Authority (REC 18/WM/0328) and the local institutional review boards for each participating site.

\subsection{Systematic review}

An electronic search of PubMed, Google Scholar and MEDLINE was performed for studies published between September 1973, corresponding to the first ultrasound description of HM in early pregnancy by Birnholz and Barnes [19] and September 2017. The search protocol was designed a priori and registered on 
PROSPERO (CRD42016050628) (http://www.crd.york.ac.uk/PROSPERO) in line with current recommendations and reported as per PRISMA 2009 guidelines (www. prisma-statement.org). The search strategy consisted of MeSH headings for "hydatidiform mole", "complete hydatidiform mole", "partial hydatidiform mole", "molar pregnancy", "gestational trophoblastic disease" AND "ultrasound diagnosis" OR "ultrasound screening" OR "ultrasound imaging" AND "early pregnancy failure" OR "miscarriage" OR "spontaneous abortion". The title and abstracts were independently assessed by two authors (MM and EJ) for content, data extraction and analysis. Additional relevant studies were identified from reference lists of reviews and editorials. The search was limited to articles published in English. Only cohort studies which provided ultrasound data confirmed by histopathology were included.

We included retrospective and prospective cohort studies. The index test consisted of at least one ultrasound examination performed during the first trimester of pregnancy in women presenting with symptoms and/or ultrasound signs of early pregnancy failure. The reference standard for confirmation of HM after evacuation was histopathologic observation of placental villi with hydropic changes and trophoblastic hyperplasia. All search results were combined in a reference database. Duplicates were removed by hand. Disagreements between the two original reviewers were resolved by discussion with the third investigator (DJ).

Clinical study characteristics and outcomes were extracted using a predesigned data extraction form including: author institution, year of publication, 
country, total number of $\mathrm{HM}$ including the number of $\mathrm{CHM}, \mathrm{PHM}$ and non-molar hydropic cases confirmed by histopathology. The primary outcome measure was the number of cases of $\mathrm{HM}, \mathrm{CHM}$ and $\mathrm{PHM}$ suggested by ultrasound imaging before surgical evacuation and gestational age at diagnosis. Secondary outcomes included number of cases in the study population and MS $\beta$-hCG levels at diagnosis.

The Quadas-2 tool for the quality assessment of diagnostic accuracy studies was used to score the methodological quality of the included articles [29]. The quality items assessed were study design and the conduct and analysis of all included studies. Each item was scored 'high' or 'low', or 'unclear' if there was insufficient information to make an accurate judgment on the risk for bias. No study was excluded based on the risk of bias assessment. Two independent reviewers (MM and EJ) undertook the quality assessment. Discrepancies were resolved with evaluation from the third reviewer (DJ).

\subsection{Statistical analysis}

Stata (STATA software (version 15; StataCorp, College Station, TX) was used to perform the statistical analysis. Standard Kurtosis analysis indicated values that were not normally distributed and they are therefore presented as median and interquartile range (IQR). Categorical variables were compared using chisquared $\left(\chi^{2}\right)$ test. A random effects model was used to combine the studies while incorporating variations among studies unless there were three or less studies contributing to the meta-analysis in which case a fixed effect model was used. 
Statistical heterogeneity was assessed with the Cochran's Q-test and the $\mathrm{I}^{2}$ statistic (the proportion of variation in study estimates because of heterogeneity rather than sampling error). Forest plots are presented to graphically summarize the study results and the pooled results. A p-value of $<0.05$ was considered significant.

\subsection{Results}

\subsection{Cohort study}

During the time period of the study, 295 cases of early pregnancy failure were identified who had an ultrasound examination in one of the two units and were confirmed as HM by histological examination at the regional referral centre. They included 142 cases from $\mathrm{KCH}$ which were used in a previous cohort study on the ultrasound imaging of HM [30]. The study group included $128 \mathrm{CHMs}$ and 167 PHMs and the overall ultrasound detection rate was significantly $(p<0.002)$ higher for CHM than for PHM (95/128 (74.2\%) versus 68/127 (40.7\%); $\left.\mathrm{X}^{2}=32.9\right)$

Accurate LMP data were available in 165 (58.9\%) cases and the median gestational age at diagnosis in these cases was 10.0 weeks (IQR 8.3;12.1). MS $\beta$-hCG levels were available in 94 of these cases at the time of the ultrasound examination including $51 \mathrm{CHMs}$ and 43 PHMs. Compared to our charts for first trimester ongoing pregnancies, MS $\beta$-hCG levels were high (> 2.0 MoM) in 20 CHMs (39.2\%) and two PHMs (4.7\%) and low (<0.5 MoM) in 5 CHMs (9.8\%) and 23 PHMs (53.5\%), respectively. Ovarian theca lutein cysts were described in 
three cases of $\mathrm{CHM}$ and one case of PHM with an overall incidence of $1.4 \%$. There were no cases of either type of HM complicated by pre-eclampsia or thyrotoxicosis at the time of diagnosis.

On follow up 19 women (6.8\%) developed GTN which required treatment. The initial diagnosis in 17 these cases was $\mathrm{CHN}$ and two remaining occurred following PHM. MS $\beta$-hCG levels at the time of the ultrasound examination were available in 14 of these cases with only five women, all diagnosed with CHMs, presenting with abnormally high readings.

\subsection{Systematic review}

From 340 citations identified, we included ten articles for the qualitative and quantitative analyses. The process of selection of the articles is summarized in

Figure 1. The characteristics and primary outcome of the corresponding studies and of the present study are presented in table 1. All studies but one [27] were retrospective and published between 1999 and 2016. Including the present cohort, a total of 1593 cases of HMs confirmed by histopathology were included in the meta-analysis.

The mean/median gestational age at diagnosis ranged between 7 weeks and 6 days and 10 weeks and 6 days (Table 1). Three cohort studies [22,31,34] included only cases of CHM and the others includes both CHM and PHM. Cases of non-molar hydropic miscarriage were included in the study group of seven cohort studies [23,25-27,31-33]. Epidemiological data were provided by three studies including the number of $\mathrm{HM}$ per deliveries [31,32] and the number of $\mathrm{HM}$ 
per early pregnancy failure27 or abnormal early pregnancy [31]. Measurements of total or MS $\beta$-hCG were reported in three studies $[22,27,31]$ with abnormally high levels in four out of 13 , four out of 15 cases and 14 out of 14 cases respectively, as tested at the time of the ultrasound diagnosis. Ovarian theca lutein cysts were only reported in two cases of $\mathrm{CHM}$ in a cohort of $24 \mathrm{HM}$ including $17 \mathrm{CHM}$ and two PHM [23]. There were no reports of $\mathrm{HM}$ complicated by pre-eclampsia or thyrotoxicosis at the time of the ultrasound examination in any of the studies. Only one study reported on four cases presenting as $\mathrm{CHM}$ that were subsequently complicated by GTN.

The quality of the studies is shown in Figure 2. Four of the included studies had a risk of bias for patient selection, three for the index test, six for the reference standard and three for flow and timing.

The meta-analysis indicated statistically significant $(P<0.001)$ level of overall heterogeneity between study estimates for the detection rates of $\mathrm{HM}$, $\mathrm{CHM}$ and PHM and these are displayed in Figs. 1 - 3. The detection rates ranged between $32.5 \%$ and $90.2 \%, 57.8 \%$ and $100 \%$ and 0 and $47.1 \%$ for $\mathrm{HM}, \mathrm{CHM}$ and PHM, respectively.

\subsection{Discussion}

Our study confirms previous findings that around a third of $\mathrm{CHM}$ and two thirds of PHM are not detected by ultrasound imaging in women presenting with first trimester miscarriages. MS $\beta$-hCG levels at the time of ultrasound 
examination are variable with $39.2 \%$ of $\mathrm{CHM}$ presenting with an abnormally high level and $53.5 \%$ of PHMs presenting with a low level. The incidence of associated complications is low but the risks of subsequently developing GTN in women with histologically confirmed HMs is similar to that reported later in pregnancy.

In PHM, the sonolucent cystic areas corresponding to hydropic molar villi are demonstrated in a small proportion of cases $[5,11]$ and are difficult to differentiate from the hydropic changes associated with prolonged retention of placental tissue following fetal demise. This can explain the higher sensitivity of ultrasound imaging in diagnosing CHM compared to PHM in early pregnancy failure. The likelihood of ultrasound diagnosis of HM is operator-dependent and small cohort studies are more likely to be reported by expert diagnostic units. This can explain why we found substantial heterogeneity in the meta-analysis for the overall ultrasound detection rates of $\mathrm{HM}$ and for the differential diagnosis between $\mathrm{CHM}$ and $\mathrm{PHM}$ (Figures 3 to 6 ). Similarly, the results of standard pathologic examination are influenced by gestational age of the villous tissue, the expertise of the pathologist and the type of $\mathrm{HM}$, with PHM being more difficult to diagnose in products from early pregnancy failure [4]. Several authors have shown that flow cytometry analysis of DNA content to evaluate the ploidy could improve the accuracy of standard histologic examination $[3,37,38]$.

Before the advent of prenatal ultrasound diagnosis, early onset preeclampsia and hyperthyroidism were well known clinical complications of $\mathrm{CHM}$ $[39,40]$. Placentation in both CHM and PHM is very superficial with limited 
trophoblastic migration into the uterine wall $[5,41]$. The absence of plugging of the spiral arteries allows the premature entry of maternal blood into the intervillous space and can explain why vaginal bleeding is the most common presenting symptom, seen in approximately $90 \%$ of $\mathrm{HM}$ in an early pregnancy unit setting [27]. Poor placentation with incomplete transformation of the uteroplacental circulation is the main pathophysiological factor leading to preeclampsia and cases of early pre-eclampsia have been reported in ongoing PHM triploidies $[5,42,43]$. None of the patients in our cohort study nor in the articles selected for the systematic review presented with these complications. Ovarian thecal lutein cysts have been reported in $9 \%$ of second trimester $\mathrm{CHMs}[1,40]$. The data indicate that the incidence of associated complications is very low in women diagnosed an early pregnancy failure and $\mathrm{HM}$.

The risk of post-molar GTN is not affect by the gestational age at diagnosis or evacuation [40]. In our cohort study, we found that $12.3 \%$ of $\mathrm{CHM}$ and $1.4 \%$ of PHM subsequently developed GTN. In a series of 32 non-hydropic, early, histologically diagnosed CHM, eight (25\%) women developed persistent GTN44 indicating that all women with $\mathrm{HM}$, regardless of the gestational at diagnosis, are at risk of subsequent GTN. High level of inconsistency between estimates in incidence, in particular, on the long-term risks of developing GTN after early pregnancy failure did not allow for full meta-analysis of the clinical outcomes.

As observed in the present study, MShCG is less likely to be increased in PHM compared to CHM and often falls below $0.5 \mathrm{MoM}$ following fetal demise in 
PHM. Only three studies $[22,27,31]$ included in the present systematic review have reported on the hCG level at the time of the ultrasound diagnosis. Two of these studies included only cases of CHM and found high hCG in 100\% [31] and in 30\% [22] of the cases tested, respectively. Gestational age evaluation in HM relies entirely on the LMP as it cannot be confirmed by measurements of the fetal crown-rump length in all $\mathrm{CHM}$ and most PHM presenting as early embryonic demise with only fetal remnants. In addition, in our cohort, around $40 \%$ of patients could not provide an accurate LMP date. This may have an impact on the interpretation of $\beta-h C G$ levels in $\mathrm{HM}$ and in particular on its use in the clinical differential diagnosis between PHM or non-molar early pregnancy failure. In the subgroup of 19 women who subsequently developed GTN, abnormally high levels MS $\beta$-hCG levels at the time of the ultrasound examination were only reported in five cases of $\mathrm{CHM}$ out of the 14 women for which these data were available. More prospective studies are needed to evaluate the use of $\beta-h C G$ at the time of the initial ultrasound examination in the diagnosis of $\mathrm{HM}$ and in predicting the risk of subsequent GTN.

The utility and cost-effectiveness of routine examination of tissue from early pregnancy failure has been the topic continuous debates [45-47]. The gold standard for the diagnosis of a molar pregnancy is the presence of trophoblastic hyperplasia on histological examination. Around two thirds of the women in our units diagnosed with an early embryonic demise or incomplete miscarriage opt for conservative management and thus those who miscarry a $\mathrm{CHM}$ spontaneously may only be diagnosed with persistent GTN at a later stage. The 
data of our cohort study and meta-analysis also indicate that the mean/median gestation age at diagnosis ranges between 7 weeks and 6 days and 10 weeks and 6 days (Table 1). Thus before 8 weeks of gestation, $\mathrm{CHM}$ are unlikely to present with the typical molar changes and will therefore not be diagnosed as HM if no tissue is available and/or histopathologic examination is not performed. In a retrospective study of 19,457 first and second trimester miscarriages over a 3-year period, Jeffers et al. [3] found that the incidence of $\mathrm{HM}$ could be as high as 1 per 41 early pregnancy losses. In a previous study, we found that an incidence of $1 \mathrm{HM}$ per 19 cases of early embryonic demise evacuated surgically and examined histologically [27]. These data suggest that the incidence of HM in pregnancy losses is much higher in the first compared to the second trimester. Without histological confirmation, it is difficult to diagnose non-hydropic molar pregnancy based solely on ultrasound presentation. In the absence of histological confirmation of HM, these women will not be registered for follow-up and are at risk of presenting with more advanced stages of GTN and thus more likely to need surgery and combination chemotherapy than women identified early in the development of the disease [1,2].

In conclusion, HM can transform into gestational trophoblastic neoplasia and most women with HM present with early pregnancy loss. Without histological confirmation, it is difficult to diagnose non-hydropic molar pregnancy based solely on ultrasound presentation. Patients presenting with clinical symptoms of early pregnancy complications and a non-hydropic placenta on ultrasound are likely to be classified as an early embryonic demise and women opting for conservative 


\begin{abstract}
management may be subjected to delayed diagnosis and treatment. Thus, our study confirms that histopathologic examination of all products of conception in early pregnancy failure is an essential component of the diagnostic pathways and follow-up post evacuation of HMs.
\end{abstract}

\title{
Acknowledgement
}

The authors wish to thank Mr Paul Bassett (Stats consultancy Ltd, Bucks, UK) for his help with the statistical analysis. 


\section{References}

1. Seckl MJ, Sebire NJ, Berkowitz RS. Gestational trophoblastic disease. Lancet 2010;376:717-729.

2. Berkowitz RS, Goldstein DP. Current advances in the management of gestational trophoblastic disease. Gynecol Oncol 2013;128:3-5.

3. Jeffers MD, O'Dwyer P, Curran B, Leader M, Gillan JE. Partial hydatidiform mole: A common but underdiagnosed condition. A 3-year retrospective clinicopathological and DNA flow cytometric analysis. Int $\mathrm{J}$ Gynecol Path 1993;12:315-323.

4. Jauniaux E, Kadri R, Hustin J. Partial mole and triploidy: screening patients with first-trimester spontaneous abortion. Obstet Gynecol 1996; 88:616-619

5. Jauniaux E. Partial moles: from postnatal to prenatal diagnosis. Placenta 1999;20:379-88.

6. Melamed A, Gockley AA, Joseph NT, et al. Effect of race/ethnicity on risk of complete and partial molar pregnancy after adjustment for age. Gynecol Oncol 2016;143:73-6.

7. Gockley AA, Melamed A, Joseph NT, et al. The effect of adolescence and advanced maternal age on the incidence of complete and partial molar pregnancy. Gynecol Oncol 2016;140:470-473.

8. Seckl MJ, Fisher RA, Salerno G, Rees H, Paradinas FJ, Foskett M, Newlands ES. Choriocarcinoma and partial hydatidiform moles. Lancet 2000;1:36-39. 
9. Fukunaga M. Early partial hydatidiform mole: prevalence, histopathology, DNA ploidy and persistence rate. Virchows Arch 2000;437:180-184.

10. Wielsma S, Kerkmeijer L, Bekkers R, Pyman J, Tan J, Quinn M. Persistent trophoblast disease following partial molar pregnancy. Aust N Z J Obstet Gynaecol 2006;46:119-123.

11. Hancock BW, Nazir K, Everard JE. Persistent gestational trophoblastic neoplasia after partial hydatidiform mole incidence and outcome. J Reprod Med 2006;51:764-766.

12. Feltmate CM, Growdon WB, Wolfberg AJ, Goldstein DP, Genest DR, Chinchilla ME, Lieberman ES, Berkowitz RS. Clinical characteristics of persistent gestational trophoblastic neoplasia after partial hydatidiform molar pregnancy. J Reprod Med 2006;51:902-906.

13. Ngan HYS, Seckl MJ, Berkowitz RS et al. Update on the diagnosis and management of gestational trophoblastic disease. Int J Gynaecol Obstet 2018;143;Suppl 2:79-85.

14. Braga A, Mora $P$, de Melo $A C$ et al. Challenges in the diagnosis and treatment of gestational trophoblastic neoplasia worldwide. World J Clin Oncol 2019;10:28-37.

15. Allison RM. The use of the male toad test in the investigation of hydatidiform mole and chorionepithelioma. Am J Obstet Gynecol 1956;71:155-165. 
16. Jauniaux E, Verheijen R. Diagnosis and management of hydatidiform mole and its complications: 2000 years of a medical challenge. BJOG 2016;123:1183.

17. Gottesfeld KR, Taylor ES, Thompson HE, Holmes JH. Diagnosis of hydatidiform mole by ultrasound. Obstet Gynecol 1967;30:163-171.

18. Kohorn El, Blackwell RJ. The diagnosis of hydatidiform mole by ultrasonic B-scanning. J Obstet Gynaecol Br Commonw 1968;75:1014-1018.

19. Birnholz JC, Barnes AB. Early diagnosis of hydatidiform mole by ultrasound. JAMA 1973;225:1359-1360.

20. Jauniaux E. Ultrasound diagnosis and follow-up of gestational trophoblastic disease. Ultrasound Obstet Gynecol1998;11:367-377.

21. Lindholm H, Flam $F$. The diagnosis of molar pregnancy by sonography and gross morphology. Acta Obstet Gynecol Scand 1999;78:6-9.

22. Lazarus E, Hulka CA, Siewert B, Levine D. Sonographic appearance of early complete molar pregnancies. J Ultrasound Med 1999;18:589-593.

23. Benson CB, Genest DR, Bernstein MR, Soto-Wright V, Goldstein DP, Berkowitz RS. Sonographic appearance of first trimester complete hydatidiform moles. Ultrasound Obstet Gynecol 2000;6:188-191.

24. Fowler DJ, Lindsay I, Seckl MJ, Sebire NJ. Routine pre-evacuation ultrasound diagnosis of hydatidiform mole: experience of more than 1000 cases from a regional referral center. Ultrasound Obstet Gynecol 2006;27:56-60. 
25. Kirk E, Papageorghiou AT, Condous G, Bottomley C, Bourne T. The accuracy of first trimester ultrasound in the diagnosis of hydatidiform mole. Ultrasound Obstet Gynecol 2007;29:70-75.

26. Fowler DJ, Lindsay I, Seckl MJ, Sebire NJ. Histomorphometric features of hydatidiform moles in early pregnancy: relationship to detectability by ultrasound examination. Ultrasound Obstet Gynecol 2007;29:76-80.

27. Johns J, Greenwold N, Buckley S, Jauniaux E. A prospective study of ultrasound screening for molar pregnancies in missed miscarriages. Ultrasound Obstet Gynecol 2005;25:493-497.

28. Jauniaux E, Memtsa M, Johns J, Ross JA, Jurkovic D. New insights in the pathophysiology of complete hydatidiform mole. Placenta 2018;62:28-33.

29. Whiting PF, Rutjes AW, Westwood ME, Mallett S, Deeks JJ, Reitsma JB et al; QUADAS-2 Group. QUADAS-2: a revised tool for the quality assessment of diagnostic accuracy studies. Ann Intern Med 2011;155: 529-536.

30. Ross JA, Unipan A, Clarke J, Magee C, Johns J. Ultrasound diagnosis of molar pregnancy. Ultrasound 2018;26:153-159.

31. Coukos G, Makrigiannakis A, Chung J, Randall TC, Rubin SC, Benjamin I. Complete hydatidiform mole. A disease with a changing profile. J Reprod Med 199944: 698-704.

32. Gemer O, Segal S, Kopmar A, Sassoon E. The current clinical presentation of complete molar pregnancy. Arch Gynecol Obstet 2000;264:33-34. 
33. Sebire NJ, Rees H, Paradinas F, Seckl M, Newlands E. The diagnostic implications of routine ultrasound examination in histologically confirmed early molar pregnancies. Ultrasound Obstet Gynecol 2001;18:662-665.

34. Jung SI, Moon MH, Kim JA, Song MJ, Kim YJ, Lee YH. Characteristic sonographic vesicular pattern of a complete hydatidiform mole in the early first trimester. J Reprod Med 2008;53:865-868.

35. Savage JL, Maturen KE, Mowers EL, et al. Sonographic diagnosis of partial versus complete molar pregnancy: A reappraisal. J Clin Ultrasound $2017 ; 45: 72-78$.

36. Chan S, Grant EG, Chen FK, Jayasinha YM, Gulati M. Early first-trimester appearance of a hydatidiform mole on sonography: The "Snowball" sign. $\mathrm{J}$ Ultrasound Med 2016;35:1610-1612.

37. Lage JM, Berkowitz RS, Rice LW, Goldstein DP, Bernstein MR, Weinberg DS. Flow cytometric analysis of DNA content in partial hydatidiform moles with persistent gestational trophoblastic tumor. Obstet Gynecol 1991;77:111-115.

38. Niemann I, Hansen ES, Sunde L. The risk of persistent trophoblastic disease after hydatidiform mole classified by morphology and ploidy. Gynecol Oncol 2007;104:411-415.

39. Mangili G, Garavaglia E, Cavoretto P, Gentile C, Scarfone G, Rabaiotti E. Clinical presentation of hydatidiform mole in northern Italy: has it changed in the last 20 years? Am J Obstet Gynecol 2008;198:302:1-4. 
40. Sun SY, Melamed A, Goldstein DP, Bernstein MR, Horowitz NS, Moron AF, et al. Changing presentation of complete hydatidiform mole at the New England Trophoblastic Disease Center over the past three decades: does early diagnosis alter risk for gestational trophoblastic neoplasia? Gynecol Oncol 2015;138:46-49.

41. Hustin J, Jauniaux E, Schaaps JP. Histological study of the maternoembryonic interface in spontaneous abortion. Placenta 1990;11:477-486.

42. Rahimpanah F, Smoleniec J. Partial mole, triploidy and proteinuric hypertension: two case reports. Aust N Z J Obstet Gynaecol 2000;40:215218.

43. Giannattasio M, Gernone G, Pannarale G, Gesualdo L, Schena FP. Preeclampsia and fetal triploidy: a rarely reported association in nephrologic literature. J Nephrol 2002;15:74-78.

44. Miyoshi J, Ohba T, Fukunaga M, Katabuchi H. Clinical features of earlystage non-hydropic mole for the diagnosis of persistent trophoblastic disease. Obstet Gynecol 2011;118:847-853.

45. Fram KM. Histological analysis of the products of conception following first trimester abortion at Jordan University Hospital. Eur J Obstet Gynecol Reprod Biol 2002;105:147-149.

46. Tasci Y, Dilbaz S, Secilmis O, Dilbaz B, Ozfuttu A, Haberal A. Routine histopathologic analysis of product of conception following firsttrimester spontaneousmiscarriages. J Obstet Gynaecol Res 2005;31:579582. 
47. Alsibiani SA. Value of histopathologic examination of uterine products after first-trimester miscarriage. Biomed Res Int 2014;2014:863482. 


\section{Figure legends}

Fig.1: Flow diagram showing the selection of reports included in the review.

Fig 2: Summary of results of Quality Assessment of Diagnostic Accuracy Studies (QUADAS) tool for articles included in the present analysis showing the proportion of cohort studies with low, high or unclear risk of bias and concerns regarding applicability.

Figure 3: Forest plots showing heterogeneity of diagnostic rate of HM. Only first author's name is given for each reference. $E S=$ effect size; $C l=$ confidence interval.

Figure 4: Forest plots showing heterogeneity of diagnostic rate of $\mathrm{CHM}$. Only first author's name is given for each reference. $E S=$ effect size; $C l=$ confidence interval.

Figure 5: Forest plots showing heterogeneity of diagnostic rate of PHM. Only first author's name is given for each reference. $E S=$ effect size; $C l=$ confidence interval. 


\section{Please wait...}

If this message is not eventually replaced by the proper contents of the document, your PDF viewer may not be able to display this type of document.

You can upgrade to the latest version of Adobe Reader for Windows®, Mac, or Linux® by visiting http://www.adobe.com/go/reader_download.

For more assistance with Adobe Reader visit http://www.adobe.com/go/acrreader.

Windows is either a registered trademark or a trademark of Microsoft Corporation in the United States and/or other countries. Mac is a trademark of Apple Inc., registered in the United States and other countries. Linux is the registered trademark of Linus Torvalds in the U.S. and other countries. 
Table 1. Characteristics and primary outcomes of ten cohorts reporting on ultrasound imaging of hydatidiform moles (HM) in early pregnancy

\begin{tabular}{|c|c|c|c|c|c|c|}
\hline \multirow{2}{*}{$\begin{array}{l}\text { Author (Year)/ } \\
\text { Country }\end{array}$} & \multirow{2}{*}{$\begin{array}{l}\text { No of HM/ } \\
\text { Type of study }\end{array}$} & \multirow{2}{*}{$\begin{array}{l}\text { GA at } \\
\text { diagnosis } \\
\text { (week) }\end{array}$} & \multicolumn{3}{|c|}{ US diagnosis } & \multirow{2}{*}{$\begin{array}{l}\text { Histology } \\
\text { results }\end{array}$} \\
\hline & & & $\begin{array}{c}\mathrm{CHM} \\
\mathrm{n}=\end{array}$ & $\begin{array}{c}\mathrm{PHM} \\
\mathrm{n}=\end{array}$ & $\begin{array}{c}\text { non-HM } \\
n=\end{array}$ & \\
\hline$\frac{\text { Gemer et al. }^{32}}{(2000) / \text { /srael }}$ & $\begin{array}{l}41 \mathrm{HM} / \\
\text { Retrospective }\end{array}$ & $\frac{10}{\text { (mean) }}$ & 36 & 1 & $\underline{4}$ & $41 \mathrm{CHM}$ \\
\hline$\frac{\frac{\text { Jung et al. }}{}^{34}}{\text { (2008)/South }}$ & $\begin{array}{l}30 \mathrm{HM} / \\
\text { Retrospective }\end{array}$ & $\frac{7.6}{\text { (mean) }}$ & $\underline{27}$ & $\mathrm{~N} / \mathrm{A}$ & $\mathrm{N} / \mathrm{A}$ & $30 \mathrm{CHM}$ \\
\hline $\begin{array}{l}\text { Coukos et al. }^{31} \\
\text { (1999)/USA }\end{array}$ & $\begin{array}{l}24 \mathrm{HM} / \\
\text { Retrospective }\end{array}$ & $\begin{array}{l}9.5 \\
\text { (mean) }\end{array}$ & 14 & $\mathrm{~N} / \mathrm{A}$ & 10 & $14 \mathrm{CHM}$ \\
\hline $\begin{array}{l}\text { Lazarus et al. }{ }^{22} \\
\text { (1999)/USA }\end{array}$ & $\begin{array}{l}21 \mathrm{HM} / \\
\text { Retrospective }\end{array}$ & $\begin{array}{l}10.5 \\
\text { (mean) }\end{array}$ & 13 & N/A & $\mathrm{N} / \mathrm{A}$ & $21 \mathrm{CHM}$ \\
\hline $\begin{array}{l}\text { Benson et al al. }{ }^{23} \\
(2000) / \text { USA }\end{array}$ & $\begin{array}{l}24 \mathrm{HM} / \\
\text { Retrospective }\end{array}$ & $\begin{array}{l}8.7 \\
\text { (mean) }\end{array}$ & 17 & 2 & 5 & $24 \mathrm{CHM}$ \\
\hline$\frac{\text { Savage et al. }}{{ }^{35}}$ & $\frac{70 \mathrm{HM} /}{\text { Retrospective }}$ & $\frac{10.6}{\text { (mean) }}$ & 19 & 22 & $\mathrm{~N} / \mathrm{A}$ & $\frac{22 \mathrm{CHM} \&}{48 \mathrm{PHM}}$ \\
\hline $\begin{array}{l}\text { Gemer et al. } \\
(2000) / \text { /srael }\end{array}$ & $\begin{array}{l}11 \mathrm{HM} / \\
\text { Retrospective }\end{array}$ & $\begin{array}{l}10 \\
(\text { mean })\end{array}$ & 36 & 7 & 4 & $41 \mathrm{CHM}$ \\
\hline $\begin{array}{l}\text { Sebire et al. }{ }^{33} \\
(2001) / \text { UK }\end{array}$ & $\begin{array}{l}155 \mathrm{HM} / \\
\text { Retrospective }\end{array}$ & $\begin{array}{l}10 \\
\text { (median) }\end{array}$ & 37 & 16 & 36 & $\begin{array}{l}64 \text { CHM \& } \\
91 \mathrm{PHM}\end{array}$ \\
\hline $\begin{array}{l}\text { Johns et al. }{ }^{21} \\
\text { (2005)/UK }\end{array}$ & $\begin{array}{l}\text { HM/ } \\
\text { Prospective }\end{array}$ & $\leq 11$ & 10 & 16 & 5 & $\begin{array}{l}11 \mathrm{CHM} \& \\
33 \mathrm{PHM}\end{array}$ \\
\hline $\begin{array}{l}\text { Fowler et al. }{ }^{26} \\
\text { (2006)/UK }\end{array}$ & $\begin{array}{l}859 \mathrm{HM} / \\
\text { Retrospective }\end{array}$ & $\begin{array}{l}10 \\
\text { (median) }\end{array}$ & 200 & 178 & 194 & $\begin{array}{l}253 \text { CHM \& } \\
606 \text { PHM }\end{array}$ \\
\hline $\begin{array}{l}\text { Kirk et al. }{ }^{25} \\
(2007) / U K\end{array}$ & $\begin{array}{l}61 \mathrm{HM} / \\
\text { Retrospective }\end{array}$ & $\begin{array}{l}10.3 \\
\text { (mean) }\end{array}$ & 19 & 8 & 7 & $\begin{array}{l}27 \text { CHM \& } \\
27 \text { PHM }\end{array}$ \\
\hline $\begin{array}{l}\text { Jung et } a_{-}{ }^{34} \\
(2008) / S K\end{array}$ & $\begin{array}{l}\text { 30 HMt } \\
\text { Retrospective }\end{array}$ & $\begin{array}{l}7.6 \\
\text { (mean) }\end{array}$ & 27 & $\mathrm{~N} / \mathrm{A}$ & $\mathrm{N} / \mathrm{A}$ & $30 \mathrm{CHM}$ \\
\hline $\begin{array}{l}\text { Savage et al. } \\
\text { (2017)/US }\end{array}$ & $\begin{array}{l}70 \mathrm{HM} / \\
\text { Retrospective }\end{array}$ & $\begin{array}{l}10.6 \\
\text { (mean) }\end{array}$ & 19 & 22 & N/A & $\begin{array}{l}22 \text { CHM \& } \\
48 \mathrm{PHM}\end{array}$ \\
\hline $\begin{array}{l}\text { Present } \\
\text { study/UK }\end{array}$ & $\begin{array}{l}295 \mathrm{HM} / \\
\text { Retrospective }\end{array}$ & $\begin{array}{l}10.0 \\
\text { (median) }\end{array}$ & 95 & 68 & $\mathrm{~N} / \mathrm{A}$ & $\begin{array}{l}128 \text { CHM \& } \\
167 \text { PHM }\end{array}$ \\
\hline
\end{tabular}

$\mathrm{GA}=$ gestational age; $\mathrm{CHM}=$ complete hydatidiform moles; $\mathrm{PHM}=$ partial hydatidiform moles; non-HM= non-molar hydropic miscarriage. 